\title{
Maternal Disempowerment and Sever Food Insecurity as Determinants of Undernutrition Among 6-36 Month Old Children in Gurage Zone, Southern Ethiopia: Case-Control Study
}

\author{
Andamlak Dendir Egata ${ }^{1}$, Wakgari Deressa ${ }^{2}$ \\ ${ }^{1}$ College of Medicine and Health Sciences, Department of Public Health, Wolkite University, Wolkite, Ethiopia \\ ${ }^{2}$ College of Health Sciences, School of Public Health, Addis Ababa University, Addis Ababa, Ethiopia
}

Email address:

AndamlakDendir@gmail.com (A. D. Egata)

\section{To cite this article:}

Andamlak Dendir Egata, Wakgari Deressa. Maternal Disempowerment and Sever Food Insecurity as Determinants of Undernutrition among 6-36 Month Old Children in Gurage Zone, Southern Ethiopia: Case-Control Study. Journal of Food and Nutrition Sciences. Vol. 6, No. 2, 2018, pp. 46-57. doi: 10.11648/j.jfns.20180602.12

Received: June 6, 2016; Accepted: July 13, 2016; Published: February 9, 2018

\begin{abstract}
Globally, malnutrition is one of the most common causes of morbidity and mortality in children under the age of five year. The relative importance of each of the known risk factors of malnutrition including household food insecurity is likely to vary between settings. However, to the best of authors' knowledge, there is no sound empirical study that simultaneously investigates the relative importance of maternal disempowerment and food insecurity on the risk of undernutrition in $6-36$ month old children in the study area. Therefore, this study was aimed to examine role of maternal disempowerment and food insecurity on under nutrition in 6-36 month old children living in Gurage Zone. To achieve study objective, Hospital based unmatched case-control study was conducted among 6-36 month old children who visited to the selected health facility of Gurage zone. A total of 346 (116 cases and 232 controls) children were included in the study. Case participants were selected consecutively; control participants were selected by systematic sampling technique. Data were collected by using interviewer administered structured questionnaire with anthropometric measurement instrument and entered into EPI data v 3.1 and analyzed using SPSS v 21. Crude and adjusted odds ratios were calculated through simple and binary multiple logistic regressions model. The result showed that undernutrition among children was significantly associated with high maternal disempowerment [AOR 6.53 (2.77-15.34)] and severe food insecurity [AOR 2.79 (1.29.04)]. Generally, the study concluded that maternal disempowerment and severe food insecurity were independently associated with under nutrition among 6-36 month old children living in study area. Besides, Hence, enhancing the household food security and promoting mother to decide lonely or jointly with their husband on issue that affects their own self or child health, resource allocation and freedom of mobility is important to prevent under nutrition in 6-36 month old children.
\end{abstract}

Keywords: Undernutrition, Maternal Empowerment, Food Insecurity, Ethiopia, Gurage Zone

\section{Introduction}

Globally, malnutrition is one of the most common causes of morbidity and mortality in children under the age of five years [4]. Malnutrition encompasses both over nutrition and under nutrition. But, in the context of developing countries, under-nutrition is generally the main issue of concern, though industrialization and changes in eating habits have increased the prevalence of over-nutrition, malnutrition in this setup (developing country) refers to under nutrition unless specified [1]. Global estimation on child hood malnutrition revealed that 165 million children were stunted, 101million were under weight and 52 million were wasted in 2011. Africa and Asia account the ninety percent $(90 \%)$ of this statistics [5]. Malnutrition is a health outcome as well as it can increase the risk of both morbidity and mortality associated with other disease [6]. Worldwide, it is estimated that $45 \%$ of all child deaths directly and indirectly associated 
with under nutrition and hence, of 6.9 million of death occurred 3.1 million were associated with malnutrition [7].

Ethiopia is the second-most populous country in Africa that inhabits approximately 84 million people and of these; around $14 \%$ of them were children under five years of age [8]. These children and their mothers were suffering disproportionately from poor health and nutrition in the country [9]. In 2011, 44.4\%, $28.7 \%$ and $9.5 \%$ of children under the age of five year were stunted, underweight and wasted respectively [10]. Similarly $51 \%$ of all causes of death in under five year children were associated with malnutrition [10].

In Southern Nations, Nationalities and Peoples' Region (SNNPR) of Ethiopia $41.1 \%, 28.6$ and $7.4 \%$ of under five children were stunted, under weight and wasted in 2011 respectively [10]. As study done by Girmay in 2010, the prevalence of underweight, stunting and wasting in infant in Butajira hospital district sites estimated as $21.2 \%, 37.7 \%$ and $12.5 \%$ [11].

Looking at the policies on problem, the government of Ethiopia has demonstrated its policy commitment to nutrition by developing a standalone National Nutrition Strategy (NNS) and a National Nutrition Programme (NNP), along with a set of guidelines, even if the problem is not addressed well.

Reviewing the research finding on the determinant factors of malnutrition, the risk factors of malnutrition are multifaceted, complex and also operate at different levels or simultaneously and classified as immediate causes (inadequate intake of nutrients and Illnesses), underlying causes (food insecurity, poor care and sanitation), and basic causes (ecological, social, political... etc [20]. The relative importance of each of the known risk factors of malnutrition including household food insecurity is likely to vary between settings. it has long been recognized that poor socioeconomic status, low education, sub-optimal nutrition and poor environmental and personal hygiene condition, poor nutritional status of the mother as a major risk factor of under nutrition. Food insecurity is probably one of the determinant factors of malnutrition in developing countries, but its role remains unclear [37]. In particular, it is not known whether all children suffer from household food insecurity and at what extreme levels. Some studies have shown that in times of food insecurity, mothers are likely to reduce their own intakes to secure those of infants and small children [38 39]. Greater household autonomy allow women to choose the most efficient and economical use of their time. Hence, the more control a woman has over her own time and household resource, the more likely; to make a timely decision to treat her sick child after discovering an illness, to make use of health services and follow through with treatment recommendations, to have the child immunized, to obtain and prepare a special food for a child, and feed it to the child at an appropriate frequency and with the degree of patience required. She may also be more likely to make use of health services for her own care during illness, for ongoing gynecological care, and for prenatal and birthing care [23].
Many studies have looked for associations between indicators of women's empowerment and child nutrition and survival.

Given, the risk factors of malnutrition are likely to vary between settings, but nationally there is no sound empirical study that explores whether household maternal empowerment status is significantly associated with undernutrition. Besides, there were a multiple of epidemiological studies done on determinants of childhood malnutrition, but, to the best of author's knowledge, none of them simultaneously examine the role of food security and maternal empowerment status on undernutrition. This study, therefore, aimed at to examine the association between maternal empowerment and food insecurity with undernutrition in 6-36 month old children after adjusting for the other known determinant of malnutrition.

\section{Methods}

The study was conducted in Butajira town of Gurage Zone which is located in southern Ethiopia. The health centre has been offering different health care service and therapeutic feeding. Butajira hospital is the zonal hospital of Gurage Zone which constitutes a total of 144 beds and five major wards and one therapeutic feeding center. High cereal prices during the harvest and immediate post-harvest period (Nov and Dec), pest infestation of "Enset" (January -April), lack of pasture and water for livestock (April to May) and unstable summer rain fall (June to August) are the most common causes of food insecurity in the zone. The data for the study were collected during period of February 20 to April 20, 2015.

\subsection{Study Design and Population}

Health facility based unmatched case-control study design was applied to determine the existing exposure difference between case and control. Cases were those children who had Weight for height $Z<-2$ SD (wasted or Weight for age $Z<-2$ $\mathrm{SD}$ (under weight) or Height for age $\mathrm{Z}<-2 \mathrm{SD}$ (stunted) for those who had no edema or Child who had bilateral pitting edema. Controls were those children who had $\mathrm{Z}>=-2 \mathrm{SD}$ in any of anthropometric index provided that free of edema. All 6-36 month children who visited the selected health institution were considered as the source population of the study and all eligible 6-36 month old children who visited the under five outpatient department (OPD) of the selected health institution during study were considered for the study populations. while, children who visited to the selected health institution for medical purpose, a children who fallen in the age group of 6-36 month, children who had a mother as a caregiver, a child and mother who lived in Gurage zone for at least six month were included in the study population, Orphan children or children separated from his or her mother by any reason, Children with mother who can't speak and give organized information, Children with HIV (applicable only for control), Children with severe burn, coma for both population, A child with mother who had widowed, divorced 
and single marital status were excluded from study population.

The total Sample size was calculated through statistical program of Epi-info v.7. Two major exposure variables (food insecurity and maternal disempowerment) were taken in to consideration during sample size calculation and the same assumptions were used for both variables except the proportion of exposure among controls. Finally, the one which come up with maximum sample size was taken. The following assumptions were taken to

come up with the final sample size.95\% confidence level, power of $80 \%$, case to control ratio of $1: 2$, detecting 2.1 times difference in food insecurity among cases, Proportion of food insecurity among normal children $=25.3 \%$. Based on the above assumptions, with additional $10 \%$ for non response rate, total sample size required to detect the existing difference was equal to 348 with 116 cases and 232 controls. For proportionally allocating the total sample size to the purposely selected health institution, 2014 quarterly patient flow for three consecutive months was used and based on that the average monthly patient flow was calculated. Then, the total sample size that was allocated to Butajira hospital was 265 (192 controls and 73 cases and to Butajira health center is 83 (40 controls and 43 cases). In each health institution, control participants were selected by systematic sampling technique. the first control participant (in both hospital and health center) was selected by lottery method from the first three card registry at the beginning of the day; then the third order patient that was come after the first selected control was selected as the second control participant and then the whole selection procedure was continued as such daily until the allocated sample size was attained. All cases who visited to OPD of both health institutions were selected as case participant without living any interval between them if they were eligible for the study.

Structured and interviewer administered questionnaires which could measure maternal empowerment status, socioeconomic and demographic factors, child characteristics, and environmental health condition of the household and household food insecurity was adapted from literature and pre- tested on population out of study area and later, necessary modification was taken. Prestige scale and measuring board instruments were used to measure the weight and height of children. Weight was measured in undressed or with minimum clothing and the weighting scales was calibrated with known weight object regularly. The scales indicators were checked against zero reading after weighing every child and mother. Edema was checked by simultaneous pressing of the feet of the child for three second. Then, if there was bilaterally pitting the child was ascertained as a case of undernutrition. Intensive two day training was given for both the data collectors and supervisor on the objective of the study, procedure and technique that they should follow during interviewing and measuring anthropometry. During period of data collection close supervision was done by supervisor and principal investigator.

\subsection{Data Processing and Analysis}

The collected data were entered into EPI data 3.1 computer programs and exported to Statistical Package for Social Sciences version 21 for cleaning, recoding, categorizing and analyzing. To identify case and controls anthropometric data were used and analyzed manually by using WHO growth reference with WHO child growth standards and rechecked through Emergency Nutrition Action software (ENA). Other statistical analysis was done by SPSS version 21 . The wealth statuses of the households were assessed by using twelve major variables (electricity, electric mitad, fridge, automobile, television, radio, latrine type, type of household floor, land and availability of poultry and other farm animal) and analyzed through principal component analysis. Before doing principal component analysis the value of each wealth variables were recoded as " 0 " and " 1 ". Later principal component analysis was done and the result of the finding was categorized into five groups: first quintile, second quintile, third quintile, fourth quintile, fifth quintile and coded 1, 2, 3, 4 respectively. The empowerment status of mothers were assessed by using three questions that focused on decision related to resource allocation, own and child health care and mobility. The mothers were asked about whether they made decision lonely or jointly with their husband. If they responded as lonely or jointly they were categorized as "=yes" and coded " 1 " and responded as husband only they were categorized as no" and coded 0 ' and the responses from three questions were summed to produce index of empowerment. The index had shown significant internal consistency (Cronbach's alpha $=0.70$ ). Later on, those participants who had index score of 0 ' categorized as disempowered and coded 3 ; those who had score of " 1 " or " 2 " categorized as partially empowered and coded "2"; and those who had score of "3" were categorized as empowered and coded "1". Household food insecurity status of the participants was assessed by using nine generic questions of HFIAS that were developed by FANTA. The respondent were asked about question related to Anxiety and uncertainty about the household food supply, Insufficient Quality (includes variety and preferences of the type of food), Insufficient food intake and its physical consequences in the past four weeks with their frequency. By using the standard criteria of household food insecurity (access) prevalence domain, households were categorized into four level (Foods secure, and mild, moderately and severely food insecure). This domain was selected because result from complete set of questions does a better job of distinguishing the household food insecurity level than result from each individual questions. Descriptive statistics like mean, frequency and percentage were calculated as univariate analysis. To evaluate the association between a single independent variable with dependent variable crude odds ratio was used and those variable that had p-value of less than 0.05 were included in the advanced model of analysis. By using the Variance Inflation Factor (VIF) and tolerance test multicollinearity was tested among eligible independent 
variables. The result of the VIF ranges from 1.225-2.519 while the tolerance test was less than one; both were within the normal limit. Since the outcome variable was categorical type, adjusted odds ratio was calculated through binomial multiple logistic regressions model. Model fitness was checked by Hosmer and Lemeshow goodness of fit test and later $95 \%$ CI were used to test statistical significance of the association between dependent and independent variables.

Ethical clearance was obtained from research ethics committee of Addis Ababa University and permission was obtained from Gurage zone health bureau. The objective of the research, procedure that was going to be done, risk and benefit of the research, way of securing the confidentiality of the information and voluntariness of participation was explained in right way to selected participant. Finally, informed consent was obtained from the selected respondent prior to the interview.

\section{Results}

A total of 348 child-mother pairs (116 cases and 232 controls) were planned to be studied in the project but for various reason only 115 cases and 231 controls were delightful for invitation, which give us the overall response rate of $99.4 \%$.

\subsection{Respondents Socio-Demographic Characteristics}

Of those children who were included in the analysis, most of the cases (67\%) and controls (60.6\%) were Muslim. While the majority of controls were from urban area $(75.3 \%)$, more than fifty percent of cases were from rural area $(55 \%)$. The majority of mothers in both cases $(60.9 \%)$ and controls (71.1\%) had formal education. Regarding paternal education $76(66.1 \%)$ of cases and $192(83.1 \%)$ of controls were had father who had formal education. pertaining to maternal occupation only $9(7.8 \%)$ of cases and $37(16 \%)$ of controls were working as an employee in governmental and nongovernmental organization. Looking at the birth order of the participants, small proportion of cases (20.9\%) and controls $(10.4 \%)$ were found as they had fourth and above order. Small proportion of mother in both case $(10.4 \%)$ and controls2 (12.1\%) had BMI less than 18.5. (table 1).

Table 1. Socio-demographic characteristics of the mothers by the child nutritional status in Butajira Hospital and Health Center, April, 2015.

\begin{tabular}{|c|c|c|c|}
\hline \multirow{2}{*}{ Explanatory variable } & \multirow{2}{*}{ Category } & \multicolumn{2}{|c|}{ Child nutritional status } \\
\hline & & Cases No-(\%)) & Control No (\%) \\
\hline \multirow{4}{*}{ Maternal educational level } & Never attend formal school & $5(4.3 \%)$ & $38(16.5 \%)$ \\
\hline & Primary & $45(39.3 \%)$ & $108(46.8 \%)$ \\
\hline & Secondary & $20(17.4 \%)$ & $32(13.9 \%)$ \\
\hline & Vocational/Diploma & $45(39.1 \%)$ & $53(22.9 \%)$ \\
\hline \multirow{5}{*}{ Paternal level of educational } & Never attend formal School & $40(34.8 \%)$ & $39(16.9 \%)$ \\
\hline & Primary & $39(33.9 \%)$ & $85(36.8 \%)$ \\
\hline & Secondary & $23(20 \%)$ & $60(26 \%)$ \\
\hline & Vocational/Diploma & $7(6 \%)$ & $29(12.6 \%)$ \\
\hline & Higher education/Degree and above & $6(5.2 \%)$ & $18(7.8 \%)$ \\
\hline \multirow{3}{*}{ Maternal occupation } & Employer & $9(7.8 \%)$ & $37(16 \%)$ \\
\hline & Merchant & $21(18.3 \%)$ & $41(17.7 \%)$ \\
\hline & house wife & $85(73.9 \%)$ & $153(66.2 \%)$ \\
\hline \multirow{3}{*}{ Paternal occupation } & Employer & $24(20.9 \%)$ & $65(28.1 \%)$ \\
\hline & Farmer & $53(46.1 \%)$ & $61(26.4 \%)$ \\
\hline & Merchant & $38(33 \%)$ & $105(45.4 \%)$ \\
\hline \multirow{4}{*}{ Maternal age group } & $15-20$ & $6(5.2 \%)$ & $15(6.5 \%)$ \\
\hline & $21-25$ & $43(37.4 \%)$ & $88(38.1 \%)$ \\
\hline & $26-30$ & $50(43.5 \%)$ & $103(44.6 \%)$ \\
\hline & $>=31$ & $16(13.9 \%)$ & $25(10.8 \%)$ \\
\hline \multirow{2}{*}{ Maternal height } & $<=150 \mathrm{~cm}$ & $102(88.7 \%)$ & $206(89.2 \%)$ \\
\hline & $>150 \mathrm{~cm}$ & $13(11.3 \%)$ & $25(108.2 \%)$ \\
\hline \multirow{2}{*}{ Maternal BMI } & $>=18.5$ & $108(93.9 \%)$ & $202(87.4 \%)$ \\
\hline & $<18.5$ & $7(6.1 \%)$ & $29(12.6 \%)$ \\
\hline \multirow{4}{*}{ Household wealth } & $1^{\text {st }}$ quartile & $35(30.4 \%)$ & $36(15.6 \%)$ \\
\hline & $2^{\text {nd }}$ quartile & $36(31.3 \%)$ & $59(25.5 \%)$ \\
\hline & $3^{\text {rd }}$ quartile & $27(23.5 \%)$ & $83(35.9 \%)$ \\
\hline & $4^{\text {th }}$ quartile & $17(14.8 \%)$ & $53(22.9 \%)$ \\
\hline \multirow{3}{*}{ Religion } & Orthodox & $31(27 \%)$ & $74(32 \%)$ \\
\hline & Muslim & $77(67 \%)$ & $140(60.6 \%)$ \\
\hline & Protestant & $7(6.1 \%)$ & $17(7.3 \%)$ \\
\hline \multirow{2}{*}{ Residence } & Urban & $52(45.2 \%)$ & $174(75.3 \%)$ \\
\hline & Rural & $63(54.8 \%)$ & $57(24.7 \%)$ \\
\hline
\end{tabular}

\subsection{Child Characteristics}

Almost equal proportions of children in both cases (45.2\%) and controls (55.4\%) were male. Higher proportion (73\%) of children in both groups were aged 24 month and below. More than ninety five percent of cases and controls were singleton (table 2) 
Andamlak Dendir Egata and Wakgari Deressa: Maternal Disempowerment and Sever Food Insecurity as Determinants of Undernutrition Among 6-36 Month Old Children in Gurage Zone, Southern Ethiopia: Case-Control Study

Table 2. Characteristics of the study children by their nutritional status in Butajira Hospital and Health Center, Gurage Zone SNNPR, April, 2015.

\begin{tabular}{|c|c|c|c|}
\hline \multirow{2}{*}{ Explanatory variable } & \multirow{2}{*}{ Category } & \multicolumn{2}{|c|}{ Children nutritional status } \\
\hline & & Cases No (\%)) /Mean & Controls No (\%)/Mean \\
\hline \multirow{2}{*}{ Sex of child } & Male & $52(45.2 \%)$ & $128(55.4 \%)$ \\
\hline & Female & $63(54.8 \%)$ & $103(44.6 \%)$ \\
\hline \multirow{2}{*}{ Child age group } & 6-17 month & $54(47 \%)$ & $117(50.6 \%)$ \\
\hline & 18-29 month & $37(32.2 \%)$ & $74(32.0 \%)$ \\
\hline \multirow[t]{2}{*}{ Birth order } & $>=30$ month & $24(20.9 \%)$ & $40(17.3 \%)$ \\
\hline & First order & $37(32.2 \%)$ & $87(37.7 \%)$ \\
\hline \multirow[t]{2}{*}{ Twining } & Second order & $32(27.8 \%)$ & $90(39 \%)$ \\
\hline & Third order & $22(19.1 \%)$ & $30(13 \%)$ \\
\hline Height & & 74.09 & 79.22 \\
\hline Weight & & 7.88 & 10.60 \\
\hline WAZ - score & & -2.68 & -.07 \\
\hline HAZ - score & & -2.24 & -.36 \\
\hline WHZ - score & & .18 & -2.01 \\
\hline
\end{tabular}

\subsection{Environmental and Child Feeding Practice}

Almost all cases (85.2\%) and controls (93.1\%) had adequate access to improved source of water. But, greater than fifty percent $(67.8 \%)$ of cases and controls $(53.7 \%)$ had unimproved sanitation. Moreover, majority of cases $(65.2 \%)$ and controls
(45.9\%) lived in muddy floor house. About practice of child feeding, $(63.5 \%)$ of case and $(81 \%)$ control participants practiced exclusive breast feeding. More than eighty percent of cases $(80 \%)$ and controls $(87 \%)$ fed breast feeding greater than or equal to eight times (table 3 ).

Table 3. Environmental and child feeding practice of study children by their nutritional status in Butajira Hospital and Health Center, Gurage Zone SNNPR, April, 2015.

\begin{tabular}{|c|c|c|c|}
\hline \multirow{2}{*}{ Explanatory variables } & \multirow{2}{*}{ Category } & \multicolumn{2}{|c|}{ Child nutritional status } \\
\hline & & Cases & Controls \\
\hline \multirow{2}{*}{ Practice of exclusive breast feeding } & Practiced & $73(63.5 \%)$ & $187(80.9 \%)$ \\
\hline & Not practiced & $42(36.5 \%)$ & $44(19 \%)$ \\
\hline \multirow{2}{*}{ Frequency of exclusive feeding } & $<8$ times & $23(20 \%)$ & $30(13 \%)$ \\
\hline & $>=8$ times & $92(80 \%)$ & $201(87 \%)$ \\
\hline \multirow{2}{*}{ Adequate Access to improved water supply } & Yes & $98(85.2 \%)$ & $215(93.1 \%)$ \\
\hline & No & $17(14.8 \%)$ & $16(6.9 \%)$ \\
\hline \multirow{2}{*}{ Sanitation } & Improved & $37(32.2 \%)$ & $107(46.3 \%)$ \\
\hline & Unimproved & $78(67.8 \%)$ & $124(53.7 \%)$ \\
\hline \multirow{2}{*}{ Floor type } & Mud & $40(34.8 \%)$ & $125(54.1 \%)$ \\
\hline & Cement & $75(65.2 \%)$ & $106(45.9 \%)$ \\
\hline
\end{tabular}

\subsection{Indicator of Maternal Empowerment Status}

High proportion of cases (62.6\%) had mothers who couldn't decide on their own and child health care but only $25.1 \%$ controls had mothers who couldn't decide on their own and child health care. Almost thirty six percent and sixty seven percent of case and controls had mothers who could decide on both small and large household expenditure respectively. Even if the proportion varies for case and control, the proportion of mothers who could decide on their mobility to relevant places were less than fifty percent. Regarding justification for wife beating, almost sixty seven percent of (66.9\%) of cases and fifty percent of $(49.3 \%)$ controls had mothers who justified wife beating (table 4$)$.

Table 4. Indicators of maternal empowerment by study children nutritional status in Butajira Hospital and Health Center, Gurage Zone SNNPR, April, 2015.

\begin{tabular}{|c|c|c|c|}
\hline Empowerment indicators & Category & Cases & Control \\
\hline \multirow{2}{*}{ Decision maker on own and child health care } & Mother only or jointly with husband & $43(37.4 \%)$ & $173(74.9 \%)$ \\
\hline & Husband only & $72(62.6 \%)$ & $58(25.1 \%)$ \\
\hline \multirow{4}{*}{$\begin{array}{l}\text { Decision maker on both small and large household } \\
\text { expenditure } \\
\text { Decision maker on mobility to relatives, friends or health } \\
\text { institution, market }\end{array}$} & Mother only or jointly with husband & $41(35.7 \%)$ & $156(67.5 \%)$ \\
\hline & Husband only & $74(64.3 \%)$ & $75(32.5 \%)$ \\
\hline & Mother only or jointly with husband & $25(21.7 \%)$ & $107(46.3)$ \\
\hline & Husband only & $90(78.3 \%)$ & $124(53.7)$ \\
\hline Justification for wife beating & Mothers agree with at least one specified reason & $38(33 \%)$ & $117(50.6 \%)$ \\
\hline
\end{tabular}

\subsection{Maternal Empowerment Status}

By considering control over resources, freedom of movement, the autonomy to decide upon own and child health care as direct indicator of household maternal empowerment, this study explored that from 115 malnourished children included in the analysis 12.2, 39.1 and 
$49.7 \%$ of them had empowered; partially empowered and disempowered mother respectively where as of 231 children free of PEM $27.7 \%, 50.2 \%$ and $13.4 \%$ of them had empowered; partially empowered and disempowered mother respectively. Table 4 below showed that the tabular presentation of the frequency distribution empowerment status across the two population (table 5).

Table 5. Table: Maternal Empowerment status by study Children nutritional status in Butajira Hospital and Health Center, Gurage Zone, SNNPR, April, 2015.

\begin{tabular}{lll}
\hline \multirow{2}{*}{ Overall maternal empowerment status } & \multicolumn{1}{l}{ Children nutritional status } \\
\cline { 2 - 3 } & Cases & Control \\
\hline Empowered & $14(12.2 \%)$ & $64(27.7 \%)$ \\
Partially empowered & $45(39.1 \%)$ & $116(50.2 \%)$ \\
Disempowered & $56(48.7 \%)$ & $31(13.4 \%)$ \\
\hline
\end{tabular}

\subsection{Household Food Security Status}

Based on Household Food Insecurity Access Scale (HFIAS) which was developed by USAIDS, this analytical study comes up with the following finding. Of 115 malnourished participants only $34(29.6 \%)$ of them had household that assured food security where as the rest 114 (70.4\%) of them had experienced different degree of food insecurity i.e. mild to severe type food insecurity. Concerning the household food security status of controls, forty eight $(48.7 \%)$ percent of them had household who assured food security where as the rest $51.3 \%$ of them had experienced different degree of food insecurity like cases. The bar graph below showed that the frequency distribution of household food security status across the two population table 6).

Table 6. Household food security status by the study children nutritional status in Butajira Hospital and Health Center, Gurage Zone, SNNPR, April, 2015.

\begin{tabular}{lll}
\hline \multirow{2}{*}{ Food security status } & Children nutritional status & Controls \\
\cline { 2 - 3 } & Cases & $114(49.4 \%)$ \\
\hline Food secured & $34(29.6 \%)$ & $46(19.9 \%)$ \\
Mildly insecured & $18(15.7 \%)$ & $43(18.6 \%)$ \\
Moderately insecured & $23(20 \%)$ & $28(12.12)$ \\
Severely insecured & $40(34.8 \%)$ & 2 \\
\hline
\end{tabular}

\subsection{Factor Associated with Under Nutrition}

\subsubsection{Socio Demographic Characteristic with Undernutrition}

Most of socio-demographic characteristic didn't show significant association with undernutrition except residence. Compared to children from urban area, children from rural area had more risk to undernutrition [AOR 4.1 (95\% CI 1.44-12.2)] (Table 7).

Table 7. The result of multivariate analysis by socio demographic covariates of undernutrition in Butajira Hospital and Health Center, Gurage Zone, SNNPR, April, 2015.

\begin{tabular}{|c|c|c|c|c|c|c|}
\hline \multirow{2}{*}{ Explanatory variables } & & \multirow{2}{*}{ Cases $(\%)$} & \multirow{2}{*}{ Control (\%) } & \multirow{2}{*}{ AOR } & \multicolumn{2}{|c|}{ 95\% CI AOR } \\
\hline & & & & & Lower & Upper \\
\hline \multirow{4}{*}{ Maternal level of educational } & Never attend formal school & $5(4.3 \%)$ & $38(16.5 \%)$ & 1.00 & & \\
\hline & Primary & $45(39.3 \%)$ & $108(46.8 \%)$ & 1.104 & .53 & 2.28 \\
\hline & Secondary & $20(17.4 \%)$ & $32(13.9 \%)$ & 2.104 & .77 & 5.74 \\
\hline & Vocational/Diploma and above & $45(39.1 \%)$ & $53(22.9 \%)$ & .532 & .08 & 3.69 \\
\hline \multirow{5}{*}{ Paternal level of educational } & Never attend formal school & $40(34.8 \%)$ & $39(16.9 \%)$ & 1.00 & & \\
\hline & Primary & $39(33.9 \%)$ & $85(36.8 \%)$ & .73 & .34 & 1.55 \\
\hline & Secondary & $23(20 \%)$ & $60(26 \%)$ & 1.08 & .41 & 2.83 \\
\hline & Vocational/Diploma & $7(6 \%)$ & $29(12.6 \%)$ & 1.34 & .34 & 5.42 \\
\hline & Higher education/Degree and above & $6(5.2 \%)$ & $18(7.8 \%)$ & 2.16 & .45 & 10.29 \\
\hline \multirow{3}{*}{ Maternal occupation } & Employer & $9(7.8 \%)$ & $37(16 \%)$ & 1.00 & & \\
\hline & Merchant & $21(18.3 \%)$ & $41(17.7 \%)$ & 1.68 & .36 & 7.75 \\
\hline & house wife & $85(73.9 \%)$ & $153(66.2 \%)$ & 1.19 & .28 & 5.01 \\
\hline \multirow{2}{*}{ Paternal occupation } & Employer & $24(20.9 \%)$ & $65(28.1 \%)$ & 1.00 & & \\
\hline & Merchant & $38(33 \%)$ & $105(45.4 \%)$ & 1.370 & .58 & 3.21 \\
\hline \multirow{2}{*}{ Residence } & Urban & $52(45.2 \%)$ & $174(75.3 \%)$ & 1.00 & & \\
\hline & Rural & $63(54.8 \%)$ & $57(24.7 \%)$ & 4.1 & 1.44 & 12.20 \\
\hline \multirow{4}{*}{ Wealth index } & Very poor & $35(30.4 \%)$ & $36(15.6 \%)$ & 1.00 & & \\
\hline & Poor & $36(31.3 \%)$ & $59(25.5 \%)$ & .60 & .25 & 1.47 \\
\hline & Rich & $27(23.5 \%)$ & $83(35.9 \%)$ & .60 & .17 & 2.08 \\
\hline & Very rich & $17(14.8 \%)$ & $53(22.9 \%)$ & .94 & .26 & 3.38 \\
\hline
\end{tabular}




\subsubsection{Environmental Condition and Child Characteristic with Undernutrition}

Those children who didn't practice exclusive breast feeding had more likely to develop undernutrition compared to children who practiced exclusive breast feeding[AOR 2.44 (95\% CI 1.36-4.3)]. Compared to children lived in household with improved sanitation, children of households who didn't utilized improved sanitation had 1.9 times more likely to had undernutrition [AOR 1.9 (95\% CI 1.036-3.456)]. This study indicated that flooring type and access to adequate source of water had no significant association with protein energy malnutrition in study area. The birth order of the study children also not associated with undernutrition in that particular set up (table 8).

Table 8. The result of multivariate analysis by environmental and child related covariates of undernutrition in Butajira Hospital and Health Center, Gurage Zone, SNNPR, April, 2015.

\begin{tabular}{|c|c|c|c|c|c|c|}
\hline \multirow{2}{*}{ Explanatory variables } & & \multirow{2}{*}{ Cases (\%) } & \multirow{2}{*}{ Controls (\%) } & \multirow{2}{*}{ AOR } & \multicolumn{2}{|c|}{ 95\% CI AOR } \\
\hline & & & & & Lower & Lower \\
\hline \multirow{2}{*}{ Adequate Access to improved water supply } & Yes & $98(85.2 \%)$ & $215(93.1 \%)$ & 1.00 & \multirow{3}{*}{.72} & \multirow[b]{2}{*}{5.05} \\
\hline & No & $17(14.8 \%)$ & $16(6.9 \%)$ & 1.91 & & \\
\hline \multirow{2}{*}{ Sanitation } & Improved & $37(32.2 \%)$ & $107(46.3 \%)$ & 1.00 & & \multirow[b]{2}{*}{3.46} \\
\hline & Unimproved & $78(67.8 \%)$ & $124(53.7 \%)$ & 1.89 & 1.036 & \\
\hline \multirow{2}{*}{ Floor type } & Cement & $75(65.2 \%)$ & $106(45.9 \%)$ & 1.00 & \multirow[b]{2}{*}{.403} & \multirow[b]{2}{*}{1.68} \\
\hline & Mud & $40(34.8 \%)$ & $125(54.1 \%)$ & .822 & & \\
\hline Practice of exclusive breast feeding & Not practiced & $42(36.5 \%)$ & $44(19 \%)$ & 2.44 & \multirow[t]{2}{*}{1.36} & \multirow[t]{2}{*}{4.39} \\
\hline \multirow{4}{*}{ Birth order } & First order & $37(32.2 \%)$ & $87(37.7 \%)$ & 1.00 & & \\
\hline & Second order & $32(27.8 \%)$ & $90(39 \%)$ & .775 & .38 & 1.56 \\
\hline & Third order & $22(19.1 \%)$ & $30(13 \%)$ & 1.110 & .47 & 2.60 \\
\hline & $>=$ Fourth order & $24(20.9 \%)$ & $24(10.4 \%)$ & .95 & .35 & 2.53 \\
\hline
\end{tabular}

After adjusting for potential confounders, this study found that maternal empowerment and food security status of study children was independently associated with undernutrition. Compared to other children, children who had mothers who couldn't decide on their own and child health care, household resource allocation/expenditure and mobility had higher risk of undernutrition [AOR 3.9 (95 CI\% 1.87-6.13)], [AOR 2.5 (95\% CI 1.38-4.47)] and [AOR $1.94(95 \%$ CI 1.05-3.54)] respectively. Justification for wife beating which is another indicator of maternal empowerment had no association with undernutrition among study children. Compared to children lived in food secured household, children of severely food insecured household had more chance of undernutrition malnutrition [AOR 2.7 (95\% CI 1.2- 5.8)]. But mild food insecurity and moderate food insecurity had no association with undernutrition (table 9).

Table 9. The result of multi-variate analysis by maternal empowerment and food security related covariates of undernutrition in Butajira Hospital and Health Center, Gurage Zone, SNNPR, April, 2015.

\begin{tabular}{|c|c|c|c|c|c|c|}
\hline \multirow{2}{*}{ Explanatory variables } & & \multirow{2}{*}{ Cases $(\%)$} & \multirow{2}{*}{ Controls $(\%)$} & \multirow{2}{*}{ AOR } & \multicolumn{2}{|c|}{ 95\% CI AOR } \\
\hline & & & & & Lower & Upper \\
\hline \multirow{2}{*}{ Decision maker on own and child health care } & Mother only or jointly with husband & $43(37.4 \%)$ & $173(74.9 \%)$ & 1.00 & & \\
\hline & Husband only & $72(62.6 \%)$ & $58(25.1 \%)$ & 3.9 & 1.87 & 6.1 \\
\hline \multirow{5}{*}{$\begin{array}{l}\text { Decision maker on both small and large household } \\
\text { expenditure } \\
\text { Decision maker on mobility to relatives, friends or } \\
\text { health institution, market }\end{array}$} & Mother only or jointly with husband & $41(35.7 \%)$ & $156(67.5 \%)$ & 1.00 & & \\
\hline & Husband only & $74(64.3 \%)$ & $75(32.5 \%)$ & 2.5 & 1.4 & 4.5 \\
\hline & Mother only or jointly with husband & $25(21.7 \%)$ & $107(46.3)$ & 1.00 & & \\
\hline & Husband only & $90(78.3 \%)$ & $124(53.7)$ & 1.94 & 1.05 & 3.54 \\
\hline & Empowered & $14(12.2 \%)$ & $64(27.7 \%)$ & 1.00 & & \\
\hline \multirow[t]{2}{*}{ Empowerment status } & Partially disempowered & $45(39.1 \%)$ & $116(50.2 \%)$ & 1.9 & .91 & 3.98 \\
\hline & Disempowered & $56(48.7 \%)$ & $31(13.4 \%)$ & 6.07 & 2.541 & 14.48 \\
\hline \multirow{2}{*}{ Wife beating } & Unjustified & $38(33 \%)$ & $117(50.6 \%)$ & 1.00 & & \\
\hline & Justified & $77(66.9 \%)$ & $114(49.3 \%)$ & .91 & .48 & 1.72 \\
\hline \multirow{4}{*}{ Food security status } & Secured & $34(29.6 \%)$ & $114(49.3 \%)$ & 1.00 & & \\
\hline & Mildly secured & $18(15.7 \%)$ & $46(19.9 \%)$ & 1.347 & .617 & 2.94 \\
\hline & Moderately insecured & $23(20 \%)$ & $43(18.6 \%)$ & 1.51 & .69 & 3.28 \\
\hline & Severely insecured & $40(34.8 \%)$ & $28(12.1 \%)$ & 2.65 & 1.20 & 5.83 \\
\hline
\end{tabular}

\section{Discussion}

By using unmatched case-control study design, this study assessed the association of household maternal empowerment and food security status with undernutrition among children of aged 6-36 month. The study indicated that both maternal empowerment and food security status had significant association with protein energy malnutrition after other confounding factors had been taken into account.

\subsection{Maternal Empowerment and Undernutrition}

Children who had mothers who couldn't decide on their own and child health care lonely or jointly with their husband had 3.8 times more risk of undernutrition compared to the other children. This can be best explained by the fact that 
mothers who have no the autonomy to decide on their own or child health care have the less likely to make a timely decision to treat their sick child after discovering an illness; to make use of health services and follow through with treatment recommendations; to have the child immunized; to obtain and prepare a special food for a child; and feed it to the child at an appropriate frequency and with the degree of patience required. She may also have less likely to make timely decision on use of health services for her own care during illness, for ongoing gynecological care, and for prenatal and birthing care [23]. This finding was in line with that of studies done in Ethiopia, Tanzania and India [28, 29 and 30].

Maternal participation in decision making process related to household expenditure had showed significant association with undernutrition. The possibility of undernutrition among children of mother who had no the opportunity to decide on household resource allocation/expenditure was 2.5 times higher than the other children who had mother who could decide on household resource allocation/expenditure lonely or jointly with their husband. The difference may be best explained by; mothers who had the autonomy to decide on household resources allocation/expenditure devoted a greater proportion of resources to child-centered expenditures. It may also due to maternal control over financial resources be able to effectively change the composition of household purchases. Additional explanation for rural mother may be if rural women have control over assets, they tend to favor the production of food crops that ensure food security for the family in contrast to Men who more frequently show a preference for cash crops sold on markets [21]. The finding was in line with that of studies done in North West Ethiopia, South Africa, Bangladesh and India [25, 31- 33]. But, it was inconsistent with studies done in Bangladesh and Tanzania that describes maternal participation in decision making process of household resources allocation /expenditure didn't showed statistical association with undernutrition in that particular set up $[29,34]$. This difference may be due to the difference in measurement tool or context.

The risk of undernutrition had shown significant difference among children of mothers who had freedom of mobility and not. Mothers who had no freedom of mobility had 1.9 times more likely to had children with undernutrition compared to mother who had freedom of mobility. This may be due to children of mother who had no freedom of mobility have less likely to utilize preventive and curative health care service timely, less likely to assure the household food security through different marketing and agricultural activity. This finding was very consistent with study done in India [33]. Justification for wife beating which was considered as another indicator of empowerment didn't show a valid statistical significant association with protein energy malnutrition. This may be due to; the very subjective nature of the question that measured the attitude toward wife beating which may enforces even the disempowered mother not to justify wife beating. Hence, information bias secondary to reporting halfhearted information may be the best explanation. Though justification for wife beating lost its statistical significance in this study, its relative importance shouldn't be under estimated. Given the contextual setting, it is possible that this factor does not enhance the nutritional status of children but it could have important effects on other health outcomes which we didn't explored yet.

The finding on overall empowerment status of the mother found to be the first in its kind in affecting the risk of undernutrition. Children of disempowered mother had 6 times more risk of undernutrition compared to those children with empowered mother. This can be best explained by the more control a woman has over her own time, household resource and mobility, the more likely; to make a timely decision to treat her sick child after discovering an illness, to make use of health services and follow through with treatment recommendations, to have the child immunized, to obtain and prepare a special food for her child, and feed it with an appropriate frequency, secure household food security through engaging different productive work activity. She may also be more likely to make use of health services for her own care during illness, for ongoing gynecological care, and for prenatal and birthing care.

\subsection{Undernutrition and Food Insecurity}

Looking at the detail of the linkage between household food security status and protein energy malnutrition, children of severely food insecured household had 2.7 times more chance to develop undernutrition compared to children living in food secured household. The most likely explanation for the association may be, in households experiencing severe food insecurity, not all members have access to enough food, and they may have reduced food intakes, consume poorquality food, or have disrupted eating patterns which ultimately can lead to protein energy malnutrition. Compared to study done in different part of the world this finding was very consistent with studies in Nepal, East-Central Uganda, and Colombia [32, 38-40, $41-42,44]$. However, the finding is not in line with those of similar studies done in east rural Ethiopia which found that food insecurity had no significant association with undernutrition $[30,45]$. This inconsistency may be due to the copying mechanism of the food insecured household which forces mother to reduce their own intakes to secure their infants and small children. The difference may also be explained by the high prevalence of food secured household and its insufficiency to secure the nutritional wellbeing of the children. Study done in slum area of South Africa also showed inconsistent result. This inconsistency may be due to the difference in measurement tools, use of convenient sampling technique which is a potential source of selection bias, and also may be due the copying mechanism of the setup.

\subsection{Child Feeding Practice and Undernutrition}

Even if practice of exclusive breast feeding, improved sanitation, and residence were not hypothesized at the outset, they showed a significance association with undernutrition. 
Those children who didn't practice exclusive breast feeding had 2.4 times more likely to develop undernutrition compared to children who practiced exclusive breast feeding. This can be best explained by the fact that till six month exclusive breast milk can prevent repeated infection through providing all of the necessary nutrients for healthy development and important antibodies against common childhood illnesses and through preventing babies from ingesting contaminated water that could be mixed with infant formula. Hence, lack of this opportunity may compromise the nutritional status of the children. Encouragingly, this finding was in line with studies done in different part of Ethiopia, Bangladesh and Nepal [28-31, 53-54].

\subsection{Environmental Health Condition and Undernutrition}

Compared to children lived in household who had improved sanitation, children of households who didn't had improved sanitation had 1.9 times more likely to had undernutrition. The observed difference may be due to children lived in household with unimproved sanitation have the more chance of exposure to repeated infections like diarrhea, intestinal parasitosis and other fecal born disease that ultimately compromises the nutrient intake of the growing child. This finding is consistent with study done in Bula Hora Distracts in Somalia region of Ethiopia and Kwara State of Nigeria [51, 55]. However, in done in southern and North West of Ethiopia sanitation had no a valid statistical association with undernutrition $[28,31]$. The variation may be because of different technical definition applied for sanitation or the context. Undernutrition in the study area had no significant association with Access to adequate source of improved water. This may be due to the majority of population in both cases and controls had access to adequate source of water.

\subsection{Undernutrition and Other Associated Factors}

From all socio-demographic variables only residence had shown a significant association with undernutrition. This may be due to the similarity of background characteristic in both case and control population. Study Children lived in rural area had 4 times more likely to had undernutrition compared to children of urban area. The most likely unsuitable climate, unimproved sanitation in community from which they arrived and non utilization of different curative and preventive health service in rural area may be the explanation for the difference. Maternal educational status had no significant association with protein energy malnutrition. This can be attributable to the fact that the majority of mother had primary and above level of education and it's in sufficiency to prevent undernutrition in the area. The finding was consistent with studies done in different part of Ethiopia and Nepal [30, 45, 53, 56, and 50]. But it was inconsistent with studies in different part of the world including Ethiopia, Bangladesh, and Iraq, [31, 54, 57 and 64]. The variation in this finding may be due to the context. Age of the mother didn't show an association with our variable of interest. This can be attributable to difficulty of getting accurate age of mother and may cause to non differential exposure misclassification bias that nullify the actual effect. In this study all child characteristics were found to be non influencing factor for protein energy malnutrition. In this study twinning had no association with undernutrition; this may be explained by the fact that only 2.6 percent of cases and 0.4 percent of controls were twin. Since this sample was insufficient to detect the existing exposure difference between case and control, the result come up with its insignificant association with protein energy malnutrition. Biological characteristic like the sex and age of the child had no significant association with undernutrition in the study area.

This study had some strength. Because the finding of this study was based a prospective case control study, it could give a more strong evidence on causation compared to crosssectional and other descriptive study. This study may have some limitations. Since it is a case control study it is difficult to establish temporal relationship. Besides, Household maternal empowerment had no standard measurement and its ascertainment was based on subjective response of the participants, this difficulty may introduce exposure misclassification bias. Even if, data associated with food security was based on standard measurement tool it was based on subjective response and one month recall period these may also cause reporting and recall bias respectively and eventually differential misclassification bias. In addition, the data collection area was confined to Butajira Hospital and Health Center and hence, generalizablity of the finding to children of Gurage zone is under question mark.

\section{Conclusion and Recommendations}

Household maternal empowerment and food security status were independently associated with undernutrition among 6-36 month old children. Especially, maternal disempowerment and severe food insecurity were independently associated with undernutrition in the study area. Besides, not practicing exclusive breast feeding, utilization of unimproved sanitation and living in rural set up were found to be factor influencing the nutritional status of children. Hence the implication is there is a possibility of intervention to prevent protein energy malnutrition through enhancing food security status of the household and maternal participation in decision making processes that affects maternal and health child care, allocation of household resource/expenditure and maternal freedom of mobility. In addition, this study further recommended that promotion of improved sanitation and exclusive breast feeding would be better if they are the component of intervention by the concerned body.

\section{Competing Interests}

There is no financial and non - financial competing interest between the authors. 


\section{Acknowledgements}

This research work couldn't have been completed without the intellectual and technical support of Associate Professor Dr. Wakgari Deressa from Addis Ababa University, School of Public Health. I would like to express my deepest gratitude to Gurage Zone health bureau and other people in different managerial level for their invaluable support during data collection. I would also like to thank all data collectors and study participants, without their participation this study wouldn't have been realized.

\section{References}

[1] Bhatia P. Measuring and Interpreting Malnutrition and Mortality. Rome: World food program, Nutrition Service 2005.

[2] Solomon B. Assessment and analysis of macro and crosscutting issues contributing to malnutrition. Washington, DC, USA: International Food Policy Research Institute, 2005.

[3] http://whqlibdoc.who.int/monograph/WHO_MONO_62_\%28 chp2\%29.pdf.

[4] National nutrition programme June 2013-june 2015: 2014, Addis Ababa.

[5] Mercedes de Onis DB, Monika. Levels \& Trends in Child Malnutrition. Geneva World Health Organization and UNICEF, 2012.

[6] Blössner M, de Onis, Mercedes. Quantifying the health impact of malnutrition at national and local levels. Geneva: World Health Organization, 2005.

[7] Robert E, Cesar G, Susan P etal. Maternal and child under nutrition and overweight in low income and middle-income countries. Journal of Lancet. 2013; 382 (9890): 427-451.

[8] The 2007 housing and population census of Ethiopia. Addis Ababa, Ethiopia Central Statistical Agency 2007.

[9] Ethiopia: situation analysis for Transform Nutrition: 2013.

[10] Ethiopia Demographic and Health Survey 2011. Addis Ababa, Ethiopia: Central Statistical Agency, 2012.

[11] Girmay M. Prevalence and predictors of under nutrition among infants aged six and twelve months in Butajira, Ethiopia: The P-MaMiE Birth Cohort. BMC Public Health. 2010; 10:27.

[12] Eticha K. Prevalence and Determinants of Child Malnutrition [partial fulfillment of the requirements of the degree of Masters of Public Health]: Addis Ababa University; 2007.

[13] Haroon S, Tim De M, Michel L. Garenne etal. What's new? Investigating risk factors for severe childhood malnutrition in a high HIV prevalence South African setting. Scand Journal of Public Health Supply. 2010; 69:96-106.

[14] Benson T. Framework document for a National Nutrition Strategy for Ethiopia. International Food Policy Research Institute. Addis Ababa. 2005.

[15] Sisay M. World Vision programme for severe acute malnutrition in SNNPR. 2014.
[16] WHO/UNICEF Joint Monitoring Programmed (JMP) for Water Supply and Sanitation. 2008.

[17] Stephenson. Burden of Infection on Growth Failure. Journal of Nutrition. 1999; 129 (2): 534-38.

[18] Brown, K. Nutrition and Infection, Prologue and Progress since 1968-Diarrhea and Malnutrition. Journal of Nutrition. 2003; 133 (1): 328-32.

[19] Anju, Sidney R, Carol B. Measuring Women's Empowerment as a Variable in International Development. Research and training institute. 2002; 1 (1): 17-26.

[20] Agnes R, Quisumbing S, Ruth S etal. Empowering women to achieve food security. Washington, DC: international food policy research institute, 2001.

[21] FAO, IFAD, and ILO Gender Dimensions of Agricultural and Rural Employment: Differentiated Pathways out of Poverty. Rome: FAO, IFAD, and ILO 2010.

[22] Asian Development Bank. Gender equality and food security-women's empowerment as a tool against hunger Mandaluyong City, Philippines: Asian Development Bank, 2013.

[23] Smith, Ramakrishna U, Ndiaye A etal. The Importance of Women's Status for Child Nutrition in Developing Countries. Washington, DC: IFPRI 2003.

[24] Sethuraman K. The Role of Women's Empowerment and Domestic Violence in Child Growth and Under nutrition in a Tribal and Rural Community International Center for Research on Women. 2008.

[25] Schmidt E. The Effect of Women's Intrahousehold Bargaining Power on Child Health Outcomes in Bangladesh: Colgate University; 2012.

[26] Bhagowalia P Menon P Quisumbing R. What Dimensions of Women's Empowerment Matter Most for Child Nutrition? The International food policy research institute, 2012.

[27] Kamiya Y. Socioeconomic Determinants of Nutritional Status of Children in Lao PDR: Effects of Household and Community Factors. Journal of Health and Population Nutrition. 2011; 29 (4): 339-34.

[28] Dereje N. determinants of severe acute malnutrition among under five children in Shashogo woreda, southern Ethiopia: community based a matched case control study. International Journal of Research 2014; 1 (6): 2348-6848.

[29] Ross-S, Hannah M. Maternal Autonomy as a Protective Factor in Child Nutritional Outcome in Tanzania. Atlanta, Georgia: Georgia State University; 2010.

[30] Gudina E, Yemane B and Alemayehu W. Predictors of acute undernutrition among children aged 6 to 36 months in east rural Ethiopia: a community based nested case - control study BMC Pediatrics. 2014; 14: 91.

[31] Bantamen G. Assessment of Factors Associated with Malnutrition among under Five Years Age Children at Michael Worde, Northwest Ethiopia: A Case Control Study. Journal of Nutrition and Food Science. 2014; 4: 256.

[32] A de Villiers, M. Senekal. Determinants of growth failure in 12-24-month-old children in a high-density urban slum community in East London, South Africa European Journal of Clinical Nutrition 2002; 56 (12): 1231-41. 
[33] Mona S. Paula Glenda A etal. Maternal autonomy is inversely related to child stunting in Andhra Pradesh, India. Marten Child Nut. 2005; 5 (1): 64-74.

[34] Rushdie R. Intrahousehold Resource Allocation in Egypt: Does Women's Empowerment Lead to Greater Investments in Children? Economic Research Forum; Cairo 2004.

[35] Priya B, Agnes R, Vidhya S etal. Unpacking the Links between Women's Empowerment and Child Nutrition: Evidence Using Nationally Representative Data from Bangladesh Independent Consultant, New Delhi 2010.

[36] Jennifer A, Bilinsky P. Household Food Insecurity Access Scale (HFIAS) for Measurement of Household Food Access Indicator Guide (v. 3). Washington, D. C: 2007.

[37] Akoto O, Pooja P, David S etal. Household food insecurity and nutritional status of children aged 6 to 23 months in Kailali District of Nepal. United Nations University Food and Nutrition Bulletin. 2010; 31 (4).

[38] Saaka M, Osman M. Does Household Food Insecurity Affect the Nutritional Status of Preschool Children Aged 6-36 Months. International Journal of Population Research. 2013.

[39] Kathmandu. Household food insecurity is highly prevalent and predicts stunting among preschool children and anemia among their mothers, in Baitadi district of Nepal. Nepal: 2010.

[40] Leonardo S. Relationship between food insecurity and nutritional status of Brazilian children under the age of five. Rev Bras Epidemiol. 2013; 16 (4):984-86.

[41] Francis Lwanga RKW, Joseph KB Matovu etal. Food Security and Nutritional Status of Children Residing in Sugarcane Growing Communities of East-Central Uganda: A Crosssectional Study. Journal of Food Security. 2015; 3 (2): 34-39.

[42] Ariana P, Maureen M. Black, Carol B etal. Food Insecurity and Risk of Poor Health among US-Born Children of Immigrants. American Journal of Public Health 2009; 99 (3): 556-562.

[43] Ihab Ali, Rohana Jalil, Wan M etal. Association between household food insecurity and nutritional outcomes among children in Northeastern of Peninsular Malaysia. Journal of Nutrition Research and Practice. 2014; 8 (3): 304-11.

[44] Michelle Hackett HM-Q, 1 and Martha Cecilia Álvarez 2. Household food insecurity associated with stunting and underweight among preschool children in Antioquia, Colombia. Pan America Journal of Public Health 2009; 25 (6): 506-10.

[45] Paudel, Pradhan B, Wagle R, etal. Risk Factors for Stunting Among Children: A Community Based Case Control Study in Nepal. Kathmandu University Medical Journal. 2012; 39 (3): $18-24$.

[46] World Health Report 2007. A Safer Future: Global Public Health Security in the21st Century. Geneva: WHO, 2007.

[47] World Bank report 2007. Repositioning Nutrition as Central to Development: A Strategy for Large-Scale Action. Washington, DC: World Bank, 2006.

[48] Prüss Üstün and C. Corvalán. Preventing Disease through Healthy Environments: Towards an Estimate of the Environmental Burden of Disease. Geneva: World Health
Organization, 2006.

[49] International Bank for Reconstruction and Development report 2008. Environmental health and child survival: epidemiology, economics, experiences. Washington, DC: World Bank, 2008.

[50] Mandefro A, Mohammed T and Lamessa D. Prevalence of undernutrition and associated factors among children aged between six to fifty nine months in Bule Hora district, South Ethiopia. Journal of BioMedCentral Public Health. 2015; $15: 14$.

[51] Olagunju F, Fakayode S, Sola-Ojo F. Prevalence and Determinants of Malnutrition among Under-five Children of Farming Households in Kwara State, Nigeria. Journal of Agricultural Science. 2011; 3 (3): 173.

[52] WHO Collaborative Study Team on the Role of Breastfeeding on the Prevention of Infant Mortality. Effect of Breastfeeding on Infant and Child Mortality Due to Infectious Diseases in Less Developed Countries: A Pooled Analysis Lancet. 2000.

[53] Solomon A, Zemene T. Risk factors for severe acute malnutrition in children under the age of five: A case-control study. Ethiopian Journal of Health and Development. 2008; 22 (1): 21-5.

[54] Aklima J Shelby Y, Ahmad M etal. Prevalence and Determinants of Chronic Malnutrition among Preschool Children: A Cross-sectional Study in Dhaka City, Bangladesh. Journal of Health Population Nutrition. 2011; 29 (5): 494-499.

[55] Mandefro A, Mohammed T and Lamessa D. Prevalence of undernutrition and associated factors among children aged between six to fifty nine months in Bule Hora district, South Ethiopia: Journal of BioMedCentral Public Health. 2015; $15: 41$.

[56] Teshale F, Sahilu A and Lamessa Dube. Factors associated with stunting among children of age 24 to 59 months in Meskan district, Gurage Zone, South Ethiopia a case-control study. Journal of BioMedCentral Public Health. 2014; 14: 800.

[57] Solomon Demissie, Amare Worku. Magnitude and factors associated with malnutrition in children 6-59 months of age in pastoral community of Dollo Ado district, Somali region, Ethiopia. Science Journal of Public Health. 20131 (4):175-83.

[58] Hong R, Banta E and Betancourt J. Relationship between household wealth inequality and chronic childhood undernutrition. International Journal for Equity in Health 2006; $5: 15$.

[59] Kanjilal B, Mazumdar G, Mukherjee M etal. Nutritional status of children in India: Household socio-economic condition as the contextual determinant. International Journal for Equity in Health. 2010; 9:19.

[60] Masiye F, Chama C, Chitah B. Determinants of Child Nutritional Status in Zambia: An Analysis of a National Survey. University of Zambia 2006.

[61] Jejeebhoy S. Women's autonomy in rural India: Its dimensions, determinants and influence in the context of India: Women's empowerment and demographic processes. New York: Oxford University Press. 2000.

[62] Gender Inequality and Women's Empowerment; In-depth Analysis of the Ethiopian Demographic and Health Survey 2005. Ethiopian Society of Population Studies. 2008. 
[63] UNICEF. «Strategy for Improved Nutrition of Children and Women in Developing countries». A Policy Review. New York. 1990.
[64] Elham K, Kavosi Z, Aliasghar N, etal. Prevalence and determinants of under-nutrition among children under six: a cross-sectional survey in Fars province, Iran. International Journal of Health Policy and Development. 2014; 3 (2):71-6. 